\title{
A Case of Unrecognized Peripartum Cardiomyopathy Which Was Noticed During Emergency Cesarean Section
}

\author{
Ayşe Gül Ferlengez and Duygu Demiröz Aslan* \\ Department of Anesthesiology and Reanimation, Istanbul Educational Research Hospital, Turkey
}

*Corresponding author: Duygu Demiröz Aslan, Istanbul Educational Research Hospital, Org. Abdurrahman Nafiz Gürman Cad Etyemez, Samatya, 34098, Istanbul, Turkey

Submission: June 08, 2018; Published: 笛 July 19, 2018

\begin{abstract}
Peripartum cardiomyopathy (PPCMP) is a kind of dilated cardiomyopathy seen between the last week of gestation and the postpartum $5^{\text {th }}$ month. PPCMP may be a cause of mortality for the mother and the infant. PPCMP is associated with black race, multi parity, maternal age above 30 years, multiple pregnancy, preeclampsia, eclampsia, family history, obesity, smoking, diabetes mellitus, and hypertension, but the underlying cause is not clear [1]. In this case report, we present the diagnosis of peripartum cardiomyopathy, anesthetic management, and postoperative intensive care period in a patient who developed pulmonary edema during emergency cesarean operation. We aimed to underline that per partum cardiomyopathy should be remembered among the presumed diagnoses in case of acute pulmonary edema.
\end{abstract}

\section{Introduction}

In a definition made for the first time by Demakis et al. [2] in 1971; peripartum cardiomyopathy (PPCMP) was defined as heart failure developing within the last four months of gestation or within postpartum five months in the absence of known causes of cardiac failure [2]. Black race, multiparty, maternal age above 30 years, multiple pregnancy, preeclampsia, eclampsia, family history, obesity, smoking, diabetes mellitus, and hypertension are among the risk factors [1]. PPCMP which progresses with cardiac failure symptoms and left ventricular dysfunction in the last week of gestation or postpartum early period is a clinical picture that may be resulted in rarely seen can serious complications [3]. Echocardiography findings have been added to this definition in later period [3]. Clinical worsening shows a rapid progression in PPCMP, while half of the cases resolve spontaneously [4].

\section{Case Report}

A-26-year-old pregnant with unremarkable history of 35week P1G1 was taken to the operating room for cesarean section under emergency conditions due to fetal distress. Preanesthetic evaluation of the patient was not carried out, and physical examination in the operation room was not remarkable except for dyspnea and tachycardia. The patient was monitored with pulse oximetry, ECG, and noninvasive arterial. Admission values were: blood pressure $140 / 90 \mathrm{mmHg}$, pulse $121 / \mathrm{min}$, respiratory rate
20 breaths/min, and peripheral arterial oxygen saturation was recorded as $94 \%$. Laboratory outcomes were within the normal range. After preoxygenation with $100 \%$ oxygen for 3 minutes, anesthesia was induced by $2 \mathrm{mg} / \mathrm{Kg}$ propofol and $0.9 \mathrm{mg} / \mathrm{Kg}$ rocuronium, and the patient was intubated with Sellick's Maneuver using an endo tracheal tube of 7.0 inner diameters. Upon bubbly phlegm was seen inside the tube following the intubation, and sudden onset of pulmonary edema after a decrease in oxygen saturation; 80mg Furosemide was administered and since there was no clinical improvement, 60mg additional dose of Furosemide was given. A living baby was delivered, and APGAR 1 and 5 scores were recorded as 8 and 9; respectively. No surgical complication occurred. At the end of the operation, the intubated patient was taken to re-animation. Cardiology department was consulted and a bedside echocardiography (ECHO) was ordered. The patient was diagnosed with peripartum cardiomyopathy with the ECHO findings of $30 \%$ ejection fraction, global wall motion disorder, severely decreased left ventricular systemic functions, and moderate mitral insufficiency. Digoxin, diuretic and vasodilators were initiated and a dramatic response was received. The patient was extubated on the $3^{\text {rd }}$ day upon clinical improvement and stable vital signs. The patient was followed-up in re-animation for one week and discharged to home with recommended cardiology outpatient clinic visit. On ECHO performed after 6 months, ejection fraction was found as $60 \%$ and left ventricular functions returned to normal. 


\section{Discussion}

The real incidence and prevalence of peripartum cardiomyopathy are unknown [5]. Black race, multi parity, maternal age above 30 years, multiple pregnancy, preeclampsia, eclampsia, family history, obesity, smoking, diabetes mellitus, and hypertension are among the risk factors [1]. Although definite underlying cause of the disease is unclear, main factors include myocarditis, inflammation, immunity and genetic factors [6]. Preload is increased and after load is increased during gestation. Left ventricular wall thickness slightly increases in response to hemodynamic of pregnancy. Mild-to-moderate decrease is observed in left ventricular contraction strength especially during the last trimester and early postpartum period. It has been thought that this condition may play a role in the development of peripartum cardiomyopathy. However, there are no data to support this short-term and completely reversible condition [7].

Most of the patients with PPCMP are diagnosed in the postpartum period. Heart failure signs and symptoms may be confused with signs and symptoms such as shortness of breath, tachycardia, weakness, and ankle edema that are seen in normal gestation process and especially increase toward the end of pregnancy. However, a rapidly progressing or sudden onset clinical picture facilitates early diagnosis. Pregnant with similar complaints during pregnancy control should be questioned in details, and left ventricular systolic dysfunction should be assessed with echocardiogram. The most common presentation complaints in patients with PPCMP include shortness of breath (90\%), weakness, tachycardia (62\%), and edema (60\%) [8].

Patients with peripartum cardiomyopathy must definitely be followed-up by a team consisting of a cardiologist, a gynecologist and anesthetists. Type and timing of the delivery should be decided according to the status of the mother and infant pair. Cesarean should be planned in pregnant with rapidly worsening left ventricular systolic functions. Epidural anesthesia is a suitable option since it does not increase cardiac load. Both the mother and the infant should be observed under intensive care conditions in the postpartum period, and more care should be taken against pulmonary edema which may be caused by uterine auotransfusion. Medical therapy should be continued also in the postpartum period [9].

The presence of heart disease in pregnant women is of paramount importance for anesthetic management. Pregnant with cyanotic heart disease, cardiomyopathy, aortic and mitral valve stenosis, mechanic valve diseases, and pulmonary hypertension are the group under the highest-risk [10]. Management of these patients is challenging because rapidly changing heart rate, cardiac output, venous return, and vascular resistance especially in severe stenosis of mitral and aortic valves, and for this reason, a strict follow-up is crucial [11]. Vasopressors, drugs such as atropine may pose problems in patients with limited cardiac reserve in severe valvular stenosis. General anesthesia applications include several risks such as cardiovascular instability, difficult or incorrect intubation, and aspiration of the gastric content due to rapid induction and positive pressure ventilation [12]. Today, indications for general anesthesia have been restricted with hemodynamic instability, treatment resistant cardiac failure or patients who cannot tolerate the supine position.

\section{Conclusion}

Peripartum cardiomyopathy is a rarely seen disease in pregnant women, although it is progresses with a high rate of maternal and infant mortality. Physicians should be very careful and sceptical for the diagnosis of this disease which etiology has not yet been fully elucidated. Early diagnosis of PPCMP is important for improvement of the symptoms and decreasing mortality, as well as for the anesthesia management, and invasive miniaturization to be selected and preparations against possible complications.

\section{References}

1. Modi KA, Illum S, Jariatul K, Caldito G, Reddy PC (2009) Poor outcome of indigent patients with peripartum cardiomy-opathy in the United States. Am J Obstet Gynecol 201(2): 171.

2. Demakis JG, Rahimtoola SH (1971) Peripartum cardiomyopathy. Circulation 44(5): 964-968.

3. Manolio TA, Baughman KL, Rodeheffer R, Pearson TA, Bristow JD, et al. (1992) Prevalence and etiologic of idiopathic dilated cardiomyopathy summary of a national heart, lung and blood institute workshop. Am J Cardiol 69(17): 1458-1466.

4. Witlin AG, Mabie WC, Sibai BM (1997) Peripartum cardiomyopathy: a longitudinal echocardiographic study. Am J Obstet Gynecol 177: 11291132.

5. Fett JD, Christie LG, Carraway RD, Murphy JG (2005) Five-year prospective study of the incidence and prognosis of peri-partum cardiomiopathy at a single insitution. Mayo Clin Proc 80(12): 1602-1606.

6. Hilfiker D, Sliwa K, Drexler H (2008) Peripartum cardiomyopathy: Recent insights in its patophysiology. Trends Cardiovasc Med 18(5): 173-179.

7. Bhakta P, Biswas BK, Banerjee B (2007) Peripartum cardiomyopathy: review of the literature. Yonsei Med J 48(5): 731-747.

8. Chapa JB, Heiberger HB, Weinert L, De Cara J, Lang RM, et al. (2005) Prognostic value of echocardiography in peripartum cardiomyopathy. Obst Gynecol 105(6): 1303-1308.

9. Pyatt JR, Dubey G (2011) Peripartum cardiomyopathy: current understanding, comprehensive management review and new developments. Postgrad Med J 87(1023): 34-39.

10. Goldszmidt E, Macarthur A, Silversides C, Colman J, Sermer M, et al. (2010) Anesthetic management of a consecutive cohort of women with heart disease for labor and delivery. Int J Obstet Anesth 19(3): 266-272.

11. Akpınar 0 (2009) Pregnancy and heart valve disease. Anadolu Kardiyol Derg 9(suppl 1): 25-34.

12. (2010) Filiz tuzuner anesthesia intensive care pain. Nobel Medical Bookstore, Turkey, p. 306. 
(c) (1) Creative Commons Attribution 4.0 International License

For possible submissions Click Here
SBB

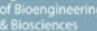
of

\section{Significances of Bioengineering \& Biosciences}

\section{Benefits of Publishing with us}

- High-level peer review and editorial services

- Freely accessible online immediately upon publication

- Authors retain the copyright to their work

- Licensing it under a Creative Commons license

- Visibility through different online platforms 